\title{
SOEP
}

SOEPpapers

SOEPpabers
on Multidisciplinary Panel Data Research

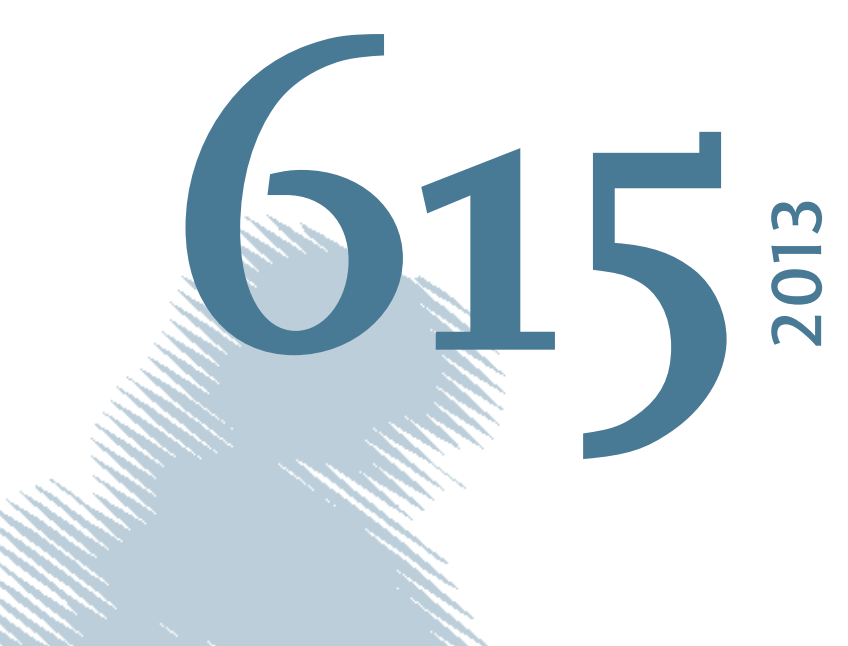

N

\section{The Influence of Child Care on Maternal Health and Mother-Child Interaction}

Alexandra Kröll and Rainald Borck 


\section{SOEPpapers on Multidisciplinary Panel Data Research}

at DIW Berlin

This series presents research findings based either directly on data from the German SocioEconomic Panel Study (SOEP) or using SOEP data as part of an internationally comparable data set (e.g. CNEF, ECHP, LIS, LWS, CHER/PACO). SOEP is a truly multidisciplinary household panel study covering a wide range of social and behavioral sciences: economics, sociology, psychology, survey methodology, econometrics and applied statistics, educational science, political science, public health, behavioral genetics, demography, geography, and sport science.

The decision to publish a submission in SOEPpapers is made by a board of editors chosen by the DIW Berlin to represent the wide range of disciplines covered by SOEP. There is no external referee process and papers are either accepted or rejected without revision. Papers appear in this series as works in progress and may also appear elsewhere. They often represent preliminary studies and are circulated to encourage discussion. Citation of such a paper should account for its provisional character. A revised version may be requested from the author directly.

Any opinions expressed in this series are those of the author(s) and not those of DIW Berlin. Research disseminated by DIW Berlin may include views on public policy issues, but the institute itself takes no institutional policy positions.

The SOEPpapers are available at

http://www.diw.de/soeppapers

\section{Editors:}

Jürgen Schupp (Sociology)

Gert G. Wagner (Social Sciences, Vice Dean DIW Graduate Center)

Conchita D'Ambrosio (Public Economics)

Denis Gerstorf (Psychology, DIW Research Director)

Elke Holst (Gender Studies, DIW Research Director)

Frauke Kreuter (Survey Methodology, DIW Research Professor)

Martin Kroh (Political Science and Survey Methodology)

Frieder R. Lang (Psychology, DIW Research Professor)

Henning Lohmann (Sociology, DIW Research Professor)

Jörg-Peter Schräpler (Survey Methodology, DIW Research Professor)

Thomas Siedler (Empirical Economics)

C. Katharina Spieß (Empirical Economics and Educational Science)

ISSN: 1864-6689 (online)

German Socio-Economic Panel Study (SOEP)

DIW Berlin

Mohrenstrasse 58

10117 Berlin, Germany

Contact: Uta Rahmann | soeppapers@diw.de 


\title{
The Influence of Child Care on Maternal Health and Mother-Child Interaction ${ }^{1}$
}

\author{
Alexandra Kröll, University of Passau \\ Rainald Borck, University of Potsdam, CESifo and DIW Berlin
}

$14^{\text {th }}$ December 2013

\begin{abstract}
In Germany, formal child care coverage rates have increased markedly over the past few decades. The expansion in coverage is particularly pronounced for under 3 year-olds. The present paper is concerned with how mothers' mental and physical health is affected by whether they place their child in formal day care or not. Furthermore, the effects of formal child care usage on mother-child interaction are examined. The analysis is based on data from the German Socio-Economic Panel for the years 2006 to 2010. This data is analysed by means of regression analyses, using local aggregate formal child care usage rates as an instrument for individual formal child care usage. The results indicate that mothers are in a worse physical condition if their children attend formal care, whereas no such effect is found with regard to mothers' mental health. Overall, there is evidence that mothers placing their children in formal care interact with them more frequently.
\end{abstract}

JEL classification: J13, I12

Keywords: child care, health status, mother-child interaction

Alexandra Kröll
University of Passau
Passau / Germany
alexandra-kroell@uni-passau.de

Alexandra Kröll

$$
\text { Passau / Germany }
$$

exandra-kroell@uni-passau.de

1 The authors are grateful to Stefan Bauernschuster and Katharina Wrohlich for helpful comments. 


\section{Introduction}

Over the past few decades, ever more parents have opted for placing their child in formal child care. In 2010, more than $17 \%$ of all children under three years old living in Western Germany and - due to historical reasons - more than $47 \%$ of those living in the East were in formal day care. Amongst those aged three to six years, almost $93 \%$ were in formal care in the West, the corresponding figure being roughly 1.5 percentage points higher in the East. ${ }^{2}$ Going along with high placement rates is an increased supply of formal child care slots. On the one hand, this opens up new possibilities for many parents, especially mothers, who formerly stayed at home to care for their children. Now, they are either free to take up paid work or have leisure time at their disposal. On the other hand, parents may experience changes in their health status as well as changes in interaction with their children as a consequence of using (formal) child care and, thereby, freeing up time for other activities.

The present paper is concerned with the effects of child care on physical and mental maternal well-being. It is important to study how maternal health is affected by child care because maternal health, in turn, affects child well-being which is of central social and political concern. It has been shown that mothers suffering from depression are less sensitive to their toddlers (cf., for example, NICHD 1999b), resulting in adverse motor and cognitive child outcomes (cf. Petterson and Albers 2001). Depressed mothers' toddlers have also been shown to receive less preventive health services such as vaccination and well-child visits, but need acute care like emergency department visits more frequently than toddlers of non-depressed mothers do (cf. Minkovitz et al. 2005, pp. 310-311). Furthermore, mothers suffering from physical pain or physical restraints may not be able to engage in physically demanding age-

2 These numbers have been calculated from data provided by the German Federal Statistical Office. Berlin is excluded. 
appropriate activities with their children, thereby inhibiting their motor skills and physical development.

Moreover, the present paper enquires how child care usage affects mother-child interaction. There are several reasons for interest in this issue. For instance, Caruso (1996) finds that although there does not seem to be any difference in mother-child interaction among infants who are placed in day care and those who are not, there do seem to be feedback effects of interaction on child outcomes conditional on day care status. Caruso (1996, pp. 130) finds mother-child interaction to affect children's cognitive development in different ways, depending on whether they are in day care or not. Nevertheless, he detects mixed evidence as to whether child care usage improves or worsens the impact of mother-child interaction on children’s cognitive outcomes.

Child care provision may fundamentally affect maternal well-being and mother-child interaction. Since mothers will tend to substitute work for time with children, they may as a result become more stressed for time or, alternatively, less stressed since they are relieved from caring for their child full-time. Further, there are income effects from taking up work which also likely affect maternal well-being and the quality of their relation with their children (see, e.g., Herbst and Tekin 2012 for further discussion).

The present paper adds to the existing literature in that it empirically investigates the relationship between formal child care usage and maternal mental and physical health, as well as mother-child interaction for Germany. There are relatively few studies on this topic (see the next section), and most of them focus on the effects of child care on mothers and children from disadvantaged socio-economic backgrounds.

The next section provides a review of related literature that covers studies on the impact of child care usage on maternal health and mother-child interaction. Section 3 contains detailed 
information on the data and estimation procedures. Estimation results are reported in Section

4. The last section concludes and recapitulates the results obtained.

\section{Related Literature}

In this paper, we examine if maternal well-being and mother-child interaction are influenced by whether a mother places her child in formal care or not. There is a very large literature on the effects of child care provision on maternal employment and children's cognitive development. Yet, there are only few previous studies concerned with similar research questions. Herbst and Tekin (2012) investigate how receiving child care subsidies affect maternal health and child-parent interaction, using data for the United States. These subsidies are granted conditional on the parents being engaged in paid employment, job training or education, creating further channels - besides increased child care usage itself - through which maternal health and child-parent interaction might be affected by the subsidies: Parents may shift time from child rearing to paid work, thereby increasing household income and enlarging consumption possibilities, but parents may also be subject to increased stress levels that worsen health outcomes and reduce the quality of child-parent interaction (for more details, see Chatterji et al. $2011^{3}$ ).

Herbst and Tekin (2012) apply different techniques to address concerns regarding nonrandom selection into subsidy receipt, such as using the distance from a family's home to the nearest public social service agency where the subsidy has to be applied for as an instrument for subsidy receipt. The central results of Herbst and Tekin (2012) are that child care

3 Chatterji et al. (2011) show for the United States that the number of maternal work hours when toddlers are aged about three months is correlated with depression and parenting stress. In addition, employed mothers' self-reported health is slightly lower compared to non-working mothers when their children are six months old, but the employment status has no influence on a mother's sensitivity to her child. Furthermore, these effects do not seem to persist, as they almost disappear when considering the first 4.5 years of a child's life. 
subsidies reduce maternal overall health by about 7 to $36 \%$ and increase mothers' depression levels and parenting stress by roughly 20 to $33 \%$ or $3 \%$, respectively. Moreover, childparent interaction is worse under subsidies: Subsidised children experience overall parental physical and psychological aggression more often. In this paper, we will investigate whether similar results hold for Germany.

The study by Baker et al. (2008) is also closely related to the present work. The authors investigate the effects of the Quebec Family Policy that stipulates tax-financed all-day kindergarten on parental health and child-parent interaction in the Canadian Province of Quebec. Using a difference-in-differences strategy, Baker et al. (2008) find that free kindergarten provision decreases the likelihood that fathers report being in excellent health, but has no statistically significant impact on women's self-reported health status, while mothers' depression scores increase and satisfaction with the spousal relationship falls. Moreover, Baker et al. (2008) find that the Quebec Family Policy increases hostile and ineffective parenting and decreases parental consistency and aversive parenting.

Brodeur and Connolly (2012), too, examine the effects of the Quebec Family Policy. Their estimations are based on a triple-differences approach: The life satisfaction of young children's parents living in Quebec (the treatment group) is compared to the life satisfaction of parents living in other Canadian provinces both before and after the implementation of the Quebec Family Policy, as well as to the life satisfaction felt by older children's parents and non-parents (who make up the control group). The authors find adverse effects of the programme on parents' subjective well-being in terms of happiness and life satisfaction. Interestingly, this policy seems to affect people differently depending on their marital status. Married individuals were found to be adversely affected, while unmarried people benefited from the programme. 
One reason for the interest in the relation between child care usage and maternal well-being lies in maternal well-being itself affecting child well-being. Numerous studies investigate how the mental and physical conditions of pregnant women affect their child's outcomes. A comprehensive review of relevant literature is provided by Almond and Currie (2010, pp. 20-21). For further studies analysing the effect of child care provision on the health of mothers of little children and mother-child interaction, see e.g. NICHD (1999a and 2003), Booth et al. (2002), Husted and Rosenkrantz-Aronson (2005) and U.S. Department of Health and Human Services, Administration for Children and Families (2010).

Overall, previous studies seem to suggest that placing her child in care worsens a mother's health status. Looking at mother-child interaction, mixed evidence is found for the influence of child care usage, although a majority of studies find that mother-child interaction suffers from a child being in care. Moreover, most of the studies analyse data from the Unites States. By contrast, one of the aims of the present paper is to shed light on the impact of formal child care usage on maternal health and mother-child interaction explicitly in Germany. Since child care institutions differ widely between the U.S. and European countries, it is interesting to contrast the U.S. evidence with evidence from other countries.

\section{Data and Estimation}

The empirical analysis uses data from the German Socio-Economic Panel (SOEP). The SOEP is an on-going survey collecting micro-data on persons and households in Germany on a sample basis. It was started in 1984 and is amended on a yearly basis. The survey enquires about many aspects of life. ${ }^{4}$ In the present case, the information collected on individual health outcomes, time use (especially with respect to mothers' interaction with their offspring) and on formal child care usage is of particular interest. There are three data files containing

\footnotetext{
${ }^{4}$ For details on the SOEP see e.g. Wagner et al. 2007.
} 
extensive information on children. One covers children aged 0-1 years, another one children aged 2-3 years, and still another one covers the 5-6 year olds.

Several variables capturing an individual's mental and physical health are provided within the SOEP, e.g., the current self-rated health status, the frequency of being pressed for time, feeling depressed, feeling well-balanced and the frequency of suffering from strong physical pains in the past four weeks. The higher the values are, the better the individual health status is. These and similar variables are standardised in order to obtain z-scores which are subsequently subjected to a linear transformation, resulting in the variables' values being standardised on a mean of 50 points and a standard deviation of 10 points. Next, the variables are further transformed exclusively into either a mental or a physical component summary scale through exploratory factor analysis (with principal components factoring and varimax rotation).

The resulting mental or physical summary variable, respectively, is again standardised to obtain z-scores and, subsequently, transformed linearly so that both variables' mean is 50 points and their standard deviation is 10 points each ${ }^{5}$ (cf. Andersen et al. 2007, particularly pp. 179 for more technical details). These two variables, the mental and physical summary scales, are employed as the dependent variables in the analysis of formal child care on maternal well-being. In these analyses, 0-1 year olds are left aside because in the present sample, only 9 out of 396 infants in this age group are in formal care, which amounts to $2.3 \%$. Due to this low number, there is not enough variation in the data within this subsample which is why it is not considered.

With respect to mother-child interaction, the SOEP provides information on how often mothers report having undertaken specific activities with their children in the past fortnight.

5 The given mean and standard deviation are valid for the 2004 wave when the mental and physical component summary scale were first introduced. Insofar, they provide a reference point for means and standard deviations obtained in subsequent waves of the SOEP. 
This information is, however, only available for children aged 2-3 or 5-6 years and is missing for new-borns. Thus, new-borns are - again - exempted from the analysis. The reported activities are singing, reading stories, visiting other families, going for a walk or to the playground, doing handicrafts and viewing picture books (this indicator is only available for 2-3 year olds) as well as playing card / dice games and going to the children's theatre / circus (the latter two being available only for 5-6 year olds). Moreover, mothers are asked about the frequency of taking their child along when going shopping, watching television and playing computer games with him or her (the latter being available only for 5-6 year olds).

In what follows, the quantity of mother-child interaction, rather than its quality, is examined because the SOEP data only provide information on the frequency of the activities. The influence of formal child care on each of the indicators for mother-child interaction is assessed separately. Binary variables indicating the frequency of a particular activity are generated. The binary variable is coded one if an activity is performed either daily or several times a week, and zero otherwise. ${ }^{6}$ Apart from that, it is desirable to construct a summary measure for mother-child interaction in case a mother scores low in some categories but more than makes up for it in the rest or, reversely, scores high on one indicator but low on all the others. As the SOEP does not contain any such summary variable, it has to be constructed manually. An intuitive way to do so is to add up the binary variables. The higher the resulting index value, the more activities a mother performs with her child.

For 5-6 year olds, three more indicators are available than for 2-3 year olds, while one interaction indicator is only available for children aged 2-3, as elaborated above. To account for the different number of indicators available, the sum of the binary variables is divided by

6 Going to the children's theatre or to the circus poses an exception because it is not an every-day activity. Thus, the binary variable is one if the mother takes her child to the children's theatre or to the circus at least once a week or more often and zero otherwise. The different coding of this indicator is also taken into account when constructing a summary measure for mother-child interaction (see below), but not explicitly mentioned in the continuous text. 
the number of its components. Thus, the index reflecting mother-child interaction takes on a maximum value of 1 if a mother performs all activities daily or several times a week. A minimum value of 0 is scored if all activities are performed either only more than once a week or never. ${ }^{7}$

The SOEP also provides information on background characteristics of individuals. Since mothers' characteristics are heterogeneous, and some of these may be correlated with child care status, it is important to control for observable differences among mothers. We include the mother's age in years, her educational attainment, immigration status, overall health status, her marital status and whether she is cohabiting with her partner, as well as whether she drinks alcohol regularly and smokes, the number of children living in the household for whom child allowances are still received and the child's sex and age in months. Additionally, binary variables indicating the respective survey year and federal state of residence are included as independent variables. Summary statistics are provided in Table 1 below.

We also control for some regional characteristics. In particular, we include the district's unemployment rate, net migration rate, fertility rate and female employment rate. Furthermore, we consider the share of females aged between 20 and 49 as well as of those aged 65 and older in all females living in a district to account for the regional age structure (see also Felfe and Lalive 2012, p. 3).

All the models presented in the results section are estimated using time and federal state fixed effects and heteroskedasticity robust White standard errors clustered on mothers. At first,

7 Because of the different number of indicators for 2-3 (9 indicators) and 5-6 year olds (11 indicators), the value of the index would be different for any two mothers performing the same activities but one with her 2-3 year old toddler and the other with her 5-6 year old child. E.g., a mother scoring only one on going for a walk and zero on all remaining interaction measures would score an interaction index of 1/9 if her child was 2-3 years and she would score a lower value of 1/11 if her child was 5-6 years old. However, when taking into account the different needs of 2-3 and 5-6 year olds, this turns out to be a convincing feature of the index as 5-6 year olds demand a broader spectrum of interaction, so going for a walk is only one among many activities and, therefore, factors less into the index than for 2-3 year olds. 
simple ordinary least squares regressions are run. OLS estimation allows making out average treatment effects, i.e., to assess the average effect of formal child care usage on maternal health or mother-child interaction. The following model is estimated by OLS:

$Y_{i d s t}=\beta_{0}+\beta_{1} D_{i d s t}+X_{i t}{ }^{\prime} \gamma+W_{d t}{ }^{\prime} \varepsilon+\alpha_{s}+\eta_{t}+u_{i d s t}$

where the respective dependent variable is denoted by $Y_{i d s t}$, $i$ being an index for the considered individual, $d$ for the district and $s$ for the federal state where individual $i$ lives, and $t$ for the respective survey year. $\beta_{0}$ is the model's constant, $X_{i t}$ is a vector of covariates covering individual characteristics, $W_{d t}$ is a vector of regional characteristics, $\alpha_{s}$ and $\eta_{t}$ are federal state and time fixed effects, respectively, and $u_{i d s t}$ is the error term. $D_{i d s t}$ is a binary variable indicating individual formal child care use - if $D_{\text {idst }}$ equals one, the respective child is placed in formal care. Hence, $\beta_{1}$ is the coefficient of interest.

When estimating the average effect of formal child care usage on maternal health and mother-child interaction, several identification issues arise. Consequently, the estimated coefficient of formal child care usage may be biased. Firstly, there may be reverse causality if, for example, mothers of poor mental or physical health tend to make use of formal child care facilities. In this case, causality would run from maternal health / mother-child interaction to formal child care usage and not in the other direction, as postulated by the regression model. Secondly, despite a rich set of controls, there may be unobserved confounding factors correlated with both formal child care usage and maternal health / mother-child interaction. A failure to include these variables into the regression model would bias the estimated coefficient of interest.

One way to tackle the causality issue is an instrumental variables strategy using a two-stage estimator. In order to correct for reverse causality or omitted variable bias, individual formal child care usage is instrumented by another variable that is both relevant (i.e., correlated with 
individual formal child care usage) and exogenous (i.e., not correlated with the error term) and, thus, a valid instrument. In the first stage, the binary variable individual formal child care usage $D_{i d s t}$ is regressed on the instrument $Z_{d t}$, the vectors of individual characteristics $X_{i t}$ and regional characteristics $W_{d t}$ described above, and the federal state and time fixed effects $\alpha_{s}$ and $\eta_{t}$. The constant is denoted by $\pi_{0}$ and the error term by $\vartheta_{i d s t}$ :

$D_{i d s t}=\pi_{0}+\pi_{1} Z_{d t}+X_{i t}{ }^{\prime} \delta+W_{d t}{ }^{\prime} \rho+\alpha_{s}+\eta_{t}+\vartheta_{i d s t}$.

In the second stage, like in (1), the respective dependent variable is denoted by $Y_{i d s t}$. As compared to the ordinary least squares regression model in (1), $\widehat{D_{l d s t}}$ are now the fitted values from the first-stage regression, making $\beta_{1}$ the coefficient of interest:

$Y_{i d s t}=\beta_{0}+\beta_{1} \widehat{D_{l d s t}}+X_{i t}{ }^{\prime} \gamma+W_{d t}{ }^{\prime} \varepsilon+\alpha_{s}+\eta_{t}+u_{i d s t}$.

Individual formal child care usage is instrumented by the (aggregate) rate of formal child care usage in the district where the respective mother and child live. ${ }^{8}$ For children aged 2-3 years, the rate of formal child care usage is calculated as the share of local children aged 0-3 years in nursery in the district population aged 0-3. It would be preferable to calculate the rate of formal child care usage as the share of local children aged 2-3 in nursery in the district population aged 2-3, but this data is not available. For those aged 5-6, the rate of formal child care usage is the ratio of local children in kindergarten and the district population aged 5-6 years. It is distinguished between children in nursery and in kindergarten because there may be substantial differences in a district's attendance rates of nurseries versus kindergartens. Especially in the Western federal states, child care coverage for 0-3 year olds still lags behind Eastern levels, whereas there is hardly any difference in coverage rates for kindergarteners (cf. Lange et al. 2008, pp. 13-14). The higher the local rate of formal child care usage, the

8 See also Felfe and Lalive (2011). Felfe and Lalive also include some consistency checks, for instance, they show that families' migration decisions are not related to regional child care provision, which might invalidate the IV approach. 
higher the probability that the child under consideration is also placed in formal child care and vice versa. The important assumption is that the district child care enrolment rate influences parents' decisions / possibilities to use formal child care, but does not directly influence mothers' health or interaction with their children.

Different regional characteristics may influence local demand for child care slots. In a lengthy administrative process (see Felfe and Lalive 2012, p. 3), regional authorities try to assess current and future demand and decide on whether to cut or expand supply. Important factors influencing demand and, thus, the number of child care slots available in a district as well as aggregate formal child care usage rates are a district's unemployment rate, net migration rate, fertility rate and female employment rate (cf. also Felfe and Lalive 2012, p. 3). For this reason, we include these variables in the regressions. Once the regional authorities have decided on how many slots to provide, the state authorities have to give their consent (otherwise the institutions will not receive any state subsidies). Consequently, it is important to consider state fixed effects to account for differences in the state authorities giving their approval. Once all of these factors are taken into account, aggregate formal child care usage rates should be as good as randomly assigned and satisfy instrument exogeneity. This makes the regional provision of child care slots a valid instrument, because the regional offer rate clearly determines individual choices, but should not be correlated with unobserved regional characteristics which influence outcomes directly.

The direct influence of aggregate formal child care usage rates on maternal health and mother-child interaction is assessed by considering OLS reduced form regressions of the outcome variable on the instrument and covariates. These reduced form regressions can be described by

$Y_{i d s t}=\beta_{0}+\varphi Z_{d t}+X_{i t}{ }^{\prime} \gamma+W_{d t}{ }^{\prime} \varepsilon+\alpha_{s}+\eta_{t}+u_{i d s t}$ 
where $\varphi$ captures the reduced form effect of local child care usage on maternal health or mother-child interaction, respectively.

Figure 1 shows the child care coverage rates in German counties in 2009. Clearly, there is a lot of variation, even within states. We use this variation within states to explain individual child care choices.
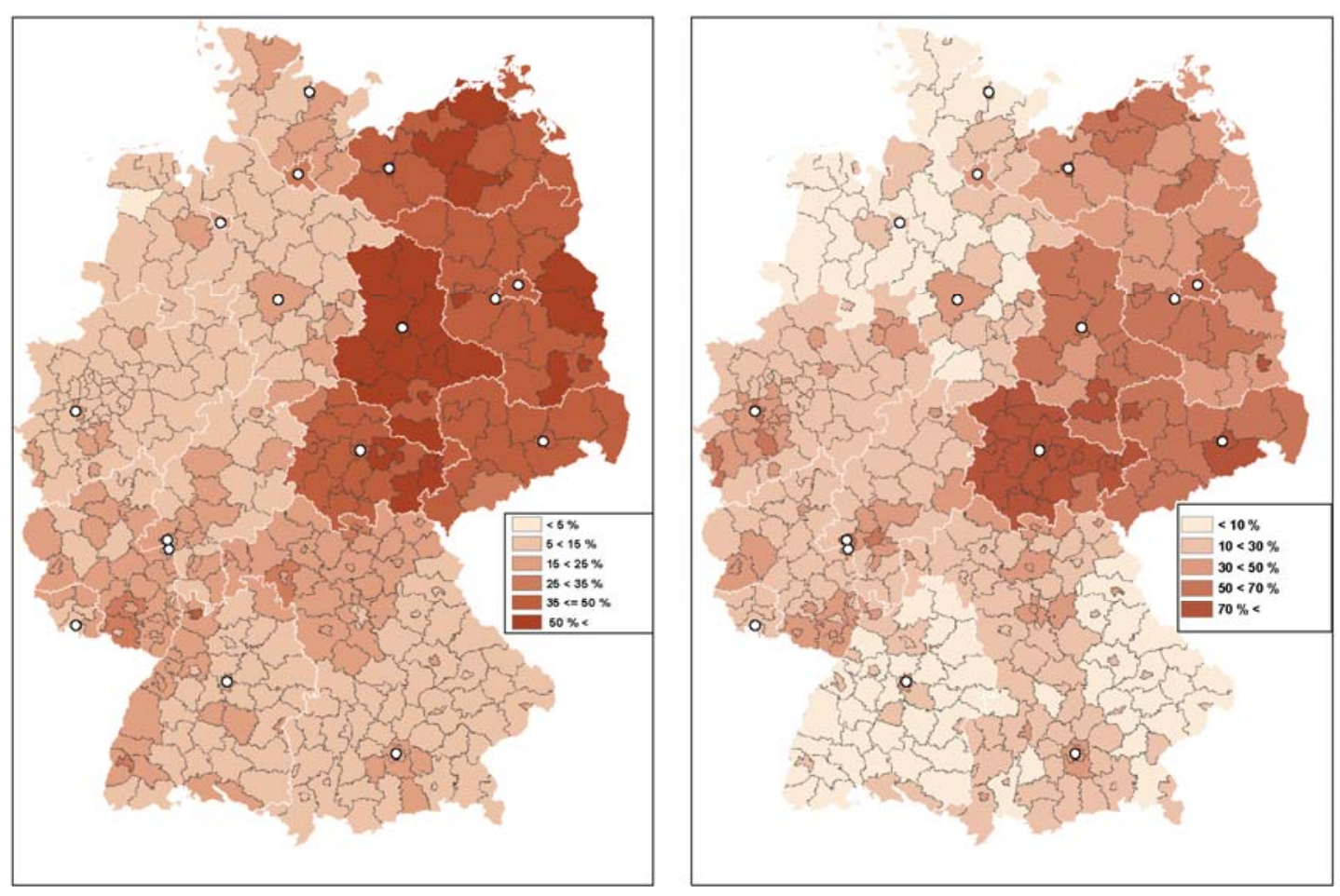

Fig. 1. Child care coverage for under three year olds (general, see left map) and three to six year olds (full-time only, see right map) in Germany, 2009. Source: Federal Statistical Office

The IV regressions control for the fact that the first stage dependent variable is binary, as described by Wooldridge (2002, pp. 623): The first stage is run as a probit regression and the resulting predicted values are used as an instrument in the second stage. Moreover, the correct standard errors are obtained by running the second stage using a two-step command instead of using an OLS estimator. A two-step estimator takes into account the two-step 
nature of the estimation and, thus, delivers the correct standard errors (see, again, Wooldridge 2002, p. 623).

Caution has to be applied when interpreting the instrumental variables estimation results. Contrary to the OLS estimator, the IV estimator does typically not produce average treatment effects because the average treatment effect can only be estimated under quite strong assumptions (see Wooldridge 2002, pp. 621 for a detailed account of these assumptions). This implies that the coefficient of interest - i.e., the coefficient on formal child care usage does not reflect the average effect of formal child care usage in IV estimations. Rather, it reflects a local average treatment effect which is a version of a marginal treatment effect. Plainly put, the marginal treatment effect captures the average effect of formal child care usage on those mothers' health / interaction with their children who are just indifferent between placing their child in care or not. A different interpretation of the marginal treatment effect is that it captures the average impact of treatment on the marginal individual that is just treated. The local average treatment effect, on the other hand, is a weighted average of the marginal treatment effects of all those who switch from non-usage to usage upon an expansion in formal child care (cf. Heckman and Vitlacil 2005, pp. 679-680 for a formal account of this relation). "Local” means that those individuals whose treatment probability is influenced the most by the instrument receive the greatest weight (cf. Stock and Watson 2012, pp. 542).

In contrast to the average treatment effect, only rather weak assumptions are needed to consistently estimate the local average treatment effect. Two necessary assumptions that must be met for an instrumental variables estimation to deliver consistent estimates are instrument relevance and exogeneity. With regard to estimating local average treatment effects, they need to be complemented by the assumption of monotonicity (cf. Angrist and Pischke 2009, p. 155, where the so-called First stage assumption corresponds to instrument relevance). 
Monotonicity implies that anyone placing their child in formal care would continue to do so (and not quit) if local formal child care usage rates went up. Presently, this last assumption might be violated if an increase in the rate of formal child care usage went along with a lower quality of service and induced some parents not to place their children in formal day care anymore.

In the present analysis, aggregate district formal child care usage is used to instrument individual formal child care usage. Arguably, whether a child is placed in formal child care or not rather depends on the offer rate, i.e. the slots available per child, than on a district's aggregate formal child care usage rate. Rates of formal child care usage may differ from the number of formal child care slots actually available per child. On the one hand, there may be vacancies if the offer rate is greater than the formal child care usage rate. On the other hand, formal child care usage rates may be higher than offer rates in case all slots are filled and some children share full-time slots, e.g. two children who are each in care half a day may share a full-time slot.

Unfortunately, though, data from which formal child care offer rates can be calculated is only available for three points in time (for the years 1994, 1998 and 2002) that do not fit with the years of availability of the remaining data. This is why the local formal child care usage rate is chosen as an instrument instead. Aggregate data on the number of children in formal child care at district level (German: Kreise) from 2006 onwards and on the respective district population aged 0-3 or 5-6 years, respectively, is provided by the German Federal Statistical Office. Taking ratios yields formal child care usage rates for toddlers (in nursery) and older children (kindergarteners). This variable is summarised in the line labelled "Local child care usage rate” in Panels A and B of Table 1. Strikingly, the maximum value of the instrument is greater than one. Values greater than one are possible in case children living in neighbouring districts of some central district $\mathrm{X}$ do not attend formal care in their home district, but in 
district X instead. So district X serves its “own” children and those from other nearby districts. If this distortion becomes too great, the instrument may lose some of its relevance, an issue examined further below. ${ }^{9}$

Taken together, the data permit to investigate the link between formal child care usage and mother-child interaction for the years 2006-2010, while the relation between formal child care usage and maternal health can be examined for the even years in this time period (because the SOEP only asks about individual health every second year, see above). Table 1 shows summary statistics of the employed variables. Due to the different number of observations and years analysed depending on whether maternal health or mother-child interaction serves as the regressand, Table 1 is split into two parts. Panel A shows summary statistics for the observations which are relevant when investigating maternal health, whereas Panel B gives summary statistics for the observations considered when looking at motherchild interaction.

9 In most German federal states, parents are legally entitled to a formal child care slot as soon as their child turns three years. One of the few exceptions is Thuringia where by law formal child care slots must be made available for children from age $2 \frac{1}{2} 2$ years onwards. In this particular case, between 30 and 36 months old toddlers in formal child care are classified as kindergarteners instead of attending a nursery, as is common practice in the remaining federal states (cf. Riedel et al. 2005, p. 82). Formal care attendance of Thuringian toddlers aged 30 to 36 months is therefore instrumented by the share of local kindergarteners instead of the share of children in nursery. 
Table 1: Summary Statistics

Panel A:

\begin{tabular}{l|ccccc} 
Variable & Observations & Mean & $\begin{array}{c}\text { Standard } \\
\text { deviation }\end{array}$ & Minimum & Maximum \\
\hline Maternal mental health & 804 & 48.18 & 9.83 & 10.92 & 70.77 \\
Maternal physical health & 804 & 54.28 & 7.15 & 24.07 & 72.27 \\
Individual formal child care usage & 804 & 0.59 & 0.49 & 0 & 1 \\
Immigration background & 804 & 0.16 & 0.36 & 0 & 1 \\
\hline Mother's age (in years) & 804 & 34.97 & 5.88 & 19 & 67 \\
Mother married and cohabiting & 804 & 0.78 & 0.42 & 0 & 1 \\
University Degree & 804 & 0.25 & 0.43 & 0 & 1 \\
Child's age (in months) & 804 & 49.22 & 18.60 & 26 & 82 \\
\hline Child is female & 804 & 0.52 & 0.50 & 0 & 1 \\
Drinking alcohol regularly & 804 & 0.07 & 0.25 & 0 & 1 \\
Smoking & 804 & 0.27 & 0.44 & 0 & 1 \\
Local child care usage rate & 804 & 0.65 & 0.38 & 0.01 & 1.06 \\
\hline Unemployment rate & 804 & 8.25 & 3.85 & 1.90 & 25.00 \\
Net migration rate & 804 & 0.00 & 0.00 & -0.02 & 0.02 \\
Female population aged 20-49 & 804 & 0.40 & 0.03 & 0.33 & 0.51 \\
Female population aged 65+ & 804 & 0.42 & 0.04 & 0.32 & 0.53 \\
\hline Fertility rate & 804 & 44.26 & 3.66 & 33.69 & 55.62 \\
Female employment rate & 804 & 0.46 & 0.15 & 0.22 & 1.07
\end{tabular}


Panel B:

\begin{tabular}{l|ccccc} 
Variable & Observations & Mean & $\begin{array}{c}\text { Standard } \\
\text { deviation }\end{array}$ & Minimum & Maximum \\
\hline Mother-child interaction index & 1401 & 0.66 & 0.20 & 0 & 1 \\
Shopping & 1401 & 0.48 & 0.50 & 0 & 1 \\
Singing & 1401 & 0.72 & 0.45 & 0 & 1 \\
Playground visits & 1401 & 0.46 & 0.50 & 0 & 1 \\
\hline Watching television & 1401 & 0.62 & 0.49 & 0 & 1 \\
Story telling/reading & 1401 & 0.86 & 0.35 & 0 & 1 \\
Individual formal child care usage & 1401 & 0.57 & 0.50 & 0 & 1 \\
Immigration background & 1401 & 0.15 & 0.36 & 0 & 1 \\
\hline Mother's age (in years) & 1401 & 34.74 & 5.84 & 19 & 67 \\
Mother married and cohabiting & 1401 & 0.79 & 0.41 & 0 & 1 \\
University Degree & 1401 & 0.24 & 0.43 & 0 & 1 \\
Child's age (in months) & 1401 & 46.96 & 17.95 & 26 & 82 \\
\hline Child is female & 1401 & 0.51 & 0.50 & 0 & 1 \\
Good / excellent maternal health & 1401 & 0.22 & 0.42 & 0 & 1 \\
Number of children in the household & 1401 & 2.07 & 1.07 & 1 & 10 \\
Local child care usage rate & 1401 & 0.62 & 0.38 & 0.01 & 1.05 \\
\hline Unemployment rate & 1401 & 8.28 & 3.81 & 1.90 & 25.00 \\
Net migration rate & 1401 & 0.00 & 0.00 & -0.02 & 0.02 \\
Female population aged 20-49 & 1401 & 0.40 & 0.03 & 0.33 & 0.51 \\
Female population aged 65+ & 1401 & 0.42 & 0.04 & 0.32 & 0.53 \\
\hline Fertility rate & 1401 & 44.04 & 3.51 & 33.69 & 55.62 \\
Female employment rate & 1401 & 0.46 & 0.15 & 0.22 & 1.07 \\
& & & & &
\end{tabular}

Source: authors' calculations

\section{Results}

To begin with, we assess the impact of formal child care usage on maternal mental health as measured by the mental component summary scale. The results are presented in Table 2. All the models are estimated with time and federal state fixed effects. Column (1) of the abovementioned table shows the results derived from an OLS estimation in a sample of 804 mothers. The coefficient of interest is the one of individual formal child care usage - the binary variable that equals one if a mother's child attends formal care. This coefficient is positive but not statistically significant. 
It can be argued that formal child care usage is endogenous. A possibility to deal with reverse causation and also with possible omitted variable bias is to apply an instrumental variables estimator. Individual formal child care usage is instrumented by local child care usage rates. The first stage is estimated as a probit model since the first stage dependent variable is binary; the results are shown in column (4). The instrument shows the expected positive sign and proves to be statistically significant at the $1 \%$ level; the first stage pseudo $\mathrm{R}^{2}$ equals 0.18 . The results of the ensuing IV estimation are shown in column (3). Note that the coefficient of formal child care usage increases markedly as compared to the OLS specification but remains statistically insignificant. The instrument's first stage F-statistic is 16.2 which is above the rule of thumb threshold 10, implying that the instrument is not weak and the statistical insignificance of the IV coefficient cannot be attributed to instrument weakness.

The striking difference between the OLS and IV coefficients can also be observed with regard to maternal physical health and mother-child interaction (see below). At least part of this difference may be attributed to the OLS coefficient representing an average treatment effect (ATE) while the IV coefficient measures a local average treatment effect (LATE). As argued above, the effect of formal child care usage on maternal health and mother-child interaction should be more pronounced for a "marginal” user than for an "average” user.

Moreover, we estimate the reduced form parameters. (See column (2) of Table 2.) The reduced form coefficient of the local formal child care usage rate turns out to be statistically insignificant. Altogether, the results presented in Table 2 suggest that within the sample analysed, there is no statistically significant impact of formal child care usage on maternal mental health. Mothers whose children attend formal care do not differ significantly in terms of their score on the mental component summary scale from those whose child is not in formal care. This is supported by the low goodness of fit measures of the regression analyses in columns (1) and (3). Even though the effect of formal child care usage on maternal mental 
health is not statistically significant at conventional levels, it is likely to be positive as 70 to $80 \%$ of its $95 \%$ confidence interval cover positive values.

With regard to the covariates, some of the regional control variables are statistically significant. Mothers appear to score higher on the mental component summary scale if they live in a district where a large proportion of the female population is quite young. Furthermore, mothers seem to enjoy better mental health when living in a district where both female employment and unemployment rate are low. However, the covariates' coefficients might not be causal effects as the models are not specified in a way so that they necessarily resemble causal effects but, rather, the covariates are included in the models in order to get causal effects of the coefficient of interest, i.e., individual formal child care usage. 
Table 2: Regression Results - Maternal Mental Health

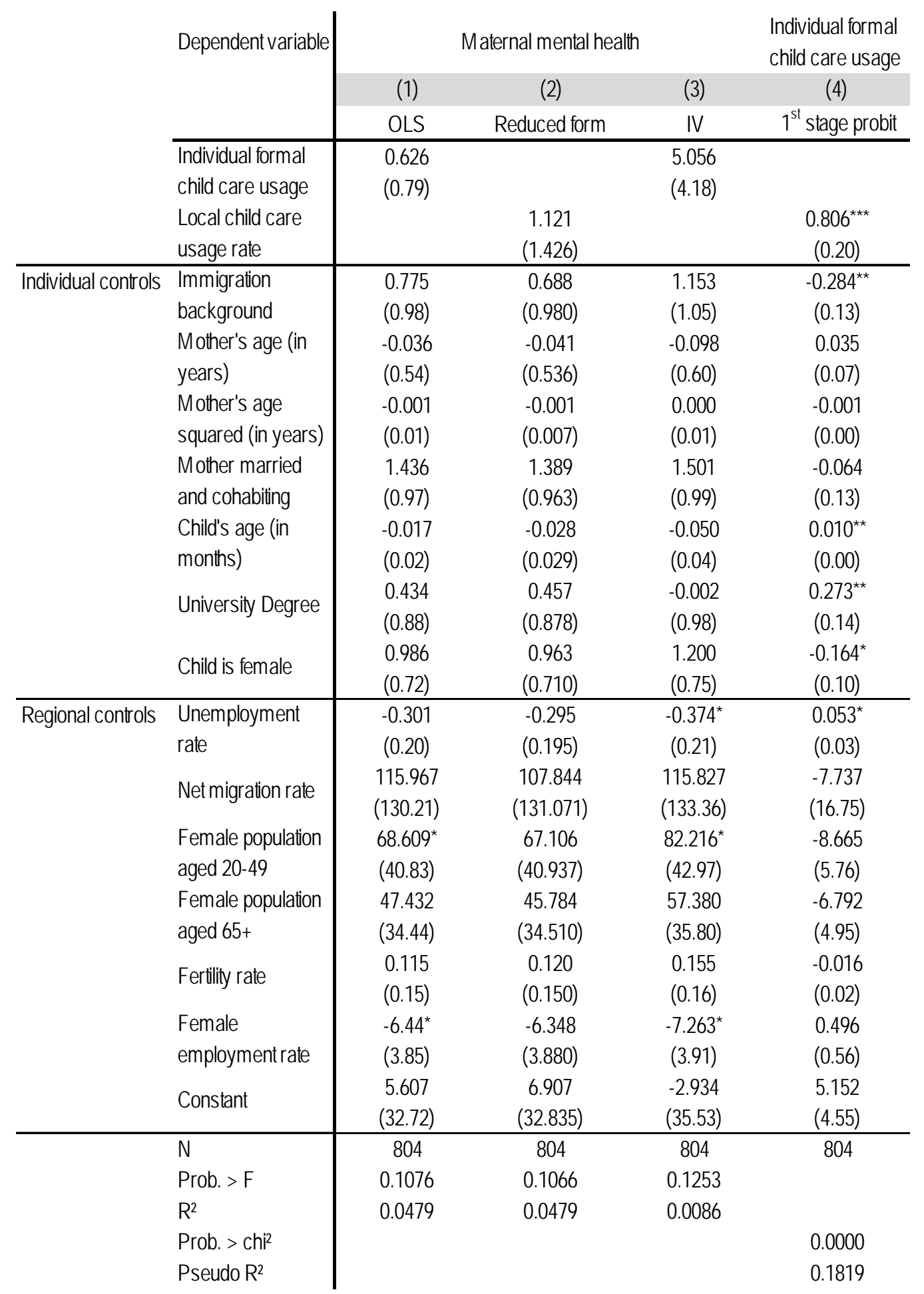

Notes: standard errors are in parentheses

*** statistically significant at the $1 \%$ level

** statistically significant at the $5 \%$ level

* statistically significant at the $10 \%$ level

Source: authors' calculations 
Maternal mental health does not seem to be affected by whether a mother relies on formal child care or not. Things look different with regard to mothers' physical health. All of the estimated models in Table 3 are statistically significant at the $1 \%$ level. The coefficient on individual formal child care usage is not significant in the OLS model in column (1). It is, however, statistically significant at the $5 \%$ level in the IV model in column (3). This model predicts that mothers whose children attend formal care score about 7.4 points lower on the physical component summary scale than others, i.e., they are in a worse physical condition. The magnitude of this effect equals more than two standard deviations. Looking at the first stage probit estimates in column (4), the instrument's coefficient is statistically significant at the $1 \%$ level (its F-statistic is 13.7) and has the expected positive sign. The first stage regression shows a pretty high pseudo $\mathrm{R}^{2}$ which equals $18.8 \%$. Consequently, instrument relevance is fulfilled. One further aspect is worth mentioning. No $\mathrm{R}^{2}$ is reported in the IV model in column (3), which happens in case the goodness of fit measure is negative. However, this should cause no trouble as the $\mathrm{R}^{2}$ has no straightforward interpretation in IV models. ${ }^{10}$ The findings of the IV model are supported by the reduced form in column (2), which suggests that child care indeed influences maternal physical health.

Again, some statistically significant covariates deserve to be mentioned briefly. It turns out that mothers who hold a university degree and those whose child is female enjoy better physical health than others. Furthermore, the models reveal that the influence of a mother's age on her physical condition follows an inverted u-shape. The models in columns (1) to (3) predict that physical health improves up to the age of 28 and deteriorates afterwards.

${ }^{10}$ For details, see Wooldridge (2006, pp. 520-521). 
Table 3: Regression Results - Maternal Physical Health

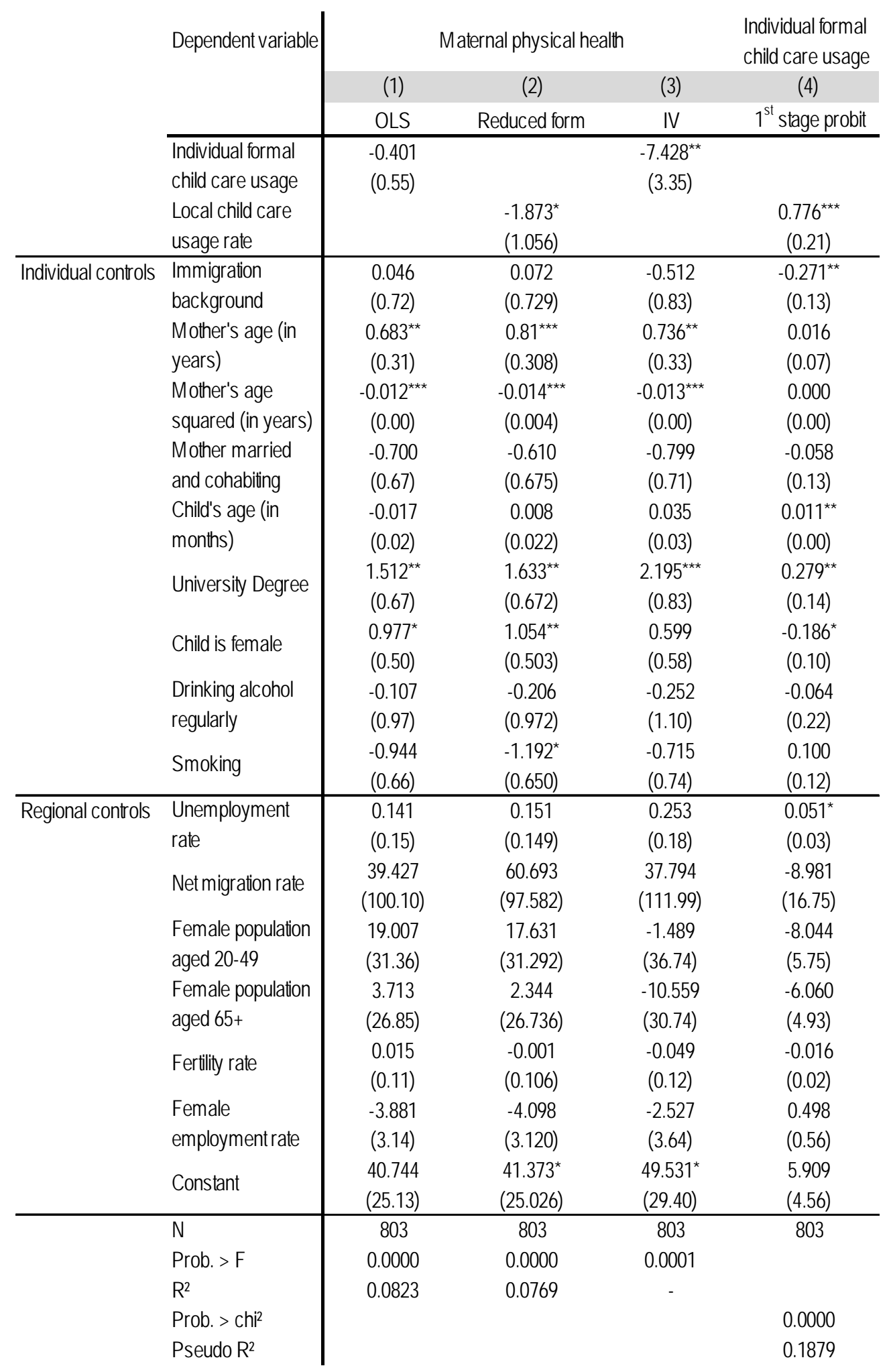

Notes: standard errors are in parentheses

*** statistically significant at the $1 \%$ level

** statistically significant at the $5 \%$ level

* statistically significant at the $10 \%$ level

Source: authors' calculations 
Turning to mother-child interaction, the results are mixed. At first, the influence of formal child care on the interaction index described in the previous section is assessed. The corresponding results are provided in Table 4. The simple ordinary least squares regression model reported in column (1) explains $22 \%$ of the variation in the data. The coefficient of interest is positive but not statistically significant. Formal child care usage, on average, does not seem to impact mother-child interaction. The picture changes, though, once an instrumental variables estimator is applied.

The instrumental variables estimation in column (3) again follows the procedure described by Wooldridge (2002, pp. 623), where the binary nature of the first stage dependent variable individual formal child care usage is taken into account. Here too, the estimated impact of formal child care on mother-child interaction is positive. What is more, the coefficient on formal child care usage is statistically significant at the $10 \%$ level. The IV model predicts that placing her child in care makes a typical mother score 0.11 points higher on the interaction index, which amounts to 1.8 standard deviations. A look at the first stage regression of individual formal child care usage on the instrument and covariates in column (4) confirms that the instrument is statistically significant at the $1 \%$ level (with an F-statistic of 29.2) and has the expected positive sign.

It seems that the OLS model either suffers from endogeneity of individual formal child care usage or from omitted variable bias. Using an IV estimator instead, the results look quite different and the model predicts a positive (causal) effect of individual formal child care usage on mother-child interaction as measured by the mother-child interaction index. The reduced form coefficient of the local child care usage rate lies in between the OLS and IV estimates (see column (2)) and is statistically significant at conventional levels, supporting the validity of our IV approach. 
Table 4: Regression Results - Mother-Child Interaction Index

\begin{tabular}{|c|c|c|c|c|c|}
\hline & Dependent variable & Mothe & r-child interaction & index & $\begin{array}{l}\text { Individual formal } \\
\text { child care usage }\end{array}$ \\
\hline & & (1) & (2) & (3) & (4) \\
\hline & & OLS & Reduced form & IV & $1^{\text {st }}$ stage probit \\
\hline & $\begin{array}{l}\text { Individual formal } \\
\text { child care usage } \\
\text { Local child care } \\
\text { usage rate }\end{array}$ & $\begin{array}{c}0.004 \\
(0.012)\end{array}$ & $\begin{array}{l}0.045^{\star \star} \\
(0.018)\end{array}$ & $\begin{array}{l}0.108^{\star} \\
(0.059)\end{array}$ & $\begin{array}{l}0.794^{\star \star \star} \\
(0.147)\end{array}$ \\
\hline Individual controls & Immigration & -0.003 & -0.004 & 0.002 & -0.155 \\
\hline & background & $(0.017)$ & $(0.017)$ & $(0.017)$ & $(0.110)$ \\
\hline & Mother's age (in & -0.003 & -0.004 & -0.006 & 0.079 \\
\hline & years) & $(0.008)$ & $(0.008)$ & $(0.008)$ & $(0.056)$ \\
\hline & Mother's age & 0.000 & 0.000 & 0.000 & -0.001 \\
\hline & squared (in years) & $(0.000)$ & $(0.000)$ & $(0.000)$ & $(0.001)$ \\
\hline & Mother married & 0.011 & 0.010 & 0.015 & -0.141 \\
\hline & and cohabiting & $(0.014)$ & $(0.014)$ & $(0.015)$ & $(0.105)$ \\
\hline & Number of children & $-0.017^{\star \star \star}$ & $-0.018^{\star \star \star}$ & $-0.013^{\star \star}$ & $-0.141^{\star \star \star}$ \\
\hline & in the household & $(0.006)$ & $(0.006)$ & $(0.006)$ & $(0.039)$ \\
\hline & Child's age (in & $-0.005^{\star \star \star}$ & $-0.005^{\star \star \star}$ & $-0.005^{\star \star \star}$ & $0.014^{\star \star \star}$ \\
\hline & months) & $(0.000)$ & $(0.000)$ & $(0.001)$ & $(0.003)$ \\
\hline & Good / excellent & $0.044^{\star \star \star}$ & $0.044^{\star \star \star}$ & $0.044^{\star \star \star}$ & 0.003 \\
\hline & maternal health & $(0.012)$ & $(0.012)$ & $(0.012)$ & $(0.101)$ \\
\hline & University Dearee & -0.011 & -0.011 & -0.020 & $0.274^{\star \star \star}$ \\
\hline & & $(0.012)$ & $(0.012)$ & $(0.014)$ & $(0.107)$ \\
\hline & Child is female & $0.026^{\star \star}$ & $0.027^{\star \star \star}$ & $0.027^{\star \star \star}$ & -0.028 \\
\hline & Clinu is Iellidile & $(0.010)$ & $(0.010)$ & $(0.010)$ & $(0.072)$ \\
\hline Regional controls & Female & 0.001 & 0.001 & 0.000 & 0.023 \\
\hline & unemployment rate & $(0.003)$ & $(0.003)$ & $(0.003)$ & $(0.024)$ \\
\hline & Netmiaration rate & 1.771 & 1.431 & 2.178 & $-21.932^{*}$ \\
\hline & Net migraton rate & $(1.579)$ & (1.591) & $(1.629)$ & (13.140) \\
\hline & Female population & $1.06^{*}$ & $1.068^{\star}$ & $1.098^{\star}$ & 0.044 \\
\hline & aged 20-49 & $(0.571)$ & $(0.570)$ & $(0.606)$ & $(4.530)$ \\
\hline & Female population & 0.780 & 0.776 & $0.91^{*}$ & -3.082 \\
\hline & aged 65+ & $(0.509)$ & $(0.508)$ & $(0.540)$ & (3.906) \\
\hline & Ferility rate & 0.001 & 0.001 & 0.002 & -0.023 \\
\hline & relunity late & $(0.002)$ & $(0.002)$ & $(0.002)$ & $(0.016)$ \\
\hline & Female & $-0.111^{*}$ & $-0.111^{*}$ & $-0.105^{\star}$ & -0.197 \\
\hline & employment rate & $(0.060)$ & $(0.060)$ & $(0.061)$ & $(0.453)$ \\
\hline & Constant & 0.194 & 0.187 & 0.119 & 1.120 \\
\hline & Conistanti & $(0.467)$ & $(0.466)$ & $(0.492)$ & (3.597) \\
\hline & $\bar{N}$ & 1401 & 1401 & 1401 & 1401 \\
\hline & Prob. $>\mathrm{F}$ & 0.0000 & 0.0000 & 0.0000 & \\
\hline & $\mathrm{R}^{2}$ & 0.2221 & 0.2252 & 0.1709 & \\
\hline & Prob > chi ${ }^{2}$ & & & & 0.0000 \\
\hline & Pseudo $\mathrm{R}^{2}$ & & & & 0.1886 \\
\hline
\end{tabular}

Notes: standard errors are in parentheses

*** statistically significant at the $1 \%$ level

** statistically significant at the $5 \%$ level

* statistically significant at the $10 \%$ level

Source: authors' calculations 
Although the covariates in Table 4 should not be given a causal interpretation, some of those that are statistically significantly different from zero deserve to be mentioned briefly. A closer look shows that the more children a mother has, the lower she scores on the interaction index, but she scores higher if her considered child is female. The same applies to mothers who report enjoying good or excellent health. Moreover, the interaction index is higher the younger the child is. Probably, older children start to interact more with friends and less and less with their parents.

These results suggest that formal child care usage does indeed influence mother-child interaction positively. Nevertheless, the interaction index is comprised of many separate interaction indicators, and the influence of formal child care usage on mother-child interaction may vary over the different indicators. Thus, the indicators which make up the index are examined separately in turn. Again, for each indicator an OLS and an IV model are estimated. Now not only the instrument is binary but the dependent variable is too. However, even though the second stage dependent variables are binary in these regressions, the second stage of the IV regressions is estimated using a plain OLS instead of a probit approach. Firstly, the results are easier to interpret when running the second stage as OLS. Secondly, and most importantly, two-step estimators with a probit second stage require strong assumptions, e.g., continuity of the endogenous regressor - an assumption that is violated in the present case. So the second stage of the IV regression needs to be estimated using an OLS estimator. To facilitate comparisons between the IV regressions and the regressions of the single interaction indicators on individual formal child care usage and covariates, the latter are also run as OLS estimations, i.e., linear probability models are estimated. ${ }^{11}$ This gain in

${ }^{11}$ One possibility to facilitate comparison between OLS and probit models is to convert the OLS estimates into marginal effects using rule of thumb conversion factors provided by Amemiya (1981, p. 1488). However, this procedure has the drawback that, when converting the IV estimates obtained in the second stage OLS regression to marginal effects so they can be compared to probit estimates (obtained from a regression of the 
convenience when estimating a linear probability model has to be weighed against a loss of precision because the binary nature of the dependent variable is disregarded. ${ }^{12}$

dependent variable on the endogenous variable and covariates), it is not clear anymore, which effect is estimated by the IV estimator. The IV estimator produces a kind of marginal effect anyway (the local average treatment effect in this case), so it is not clear how the results should be interpreted once converted to marginal effects.

12 Due to this, the model could theoretically predict a probability of individual child care usage that is negative or greater than one. In addition, only constant marginal effects are estimated in a linear probability model. With regard to the interpretation of the results, this means that, e.g., a switch from non-usage to usage of formal child care has the same effect on mother-child interaction for everybody - regardless of whether the probability of a particular mother interacting very much with her child is high or low. 
Table 5: Regression Results - Mother-Child Interaction Indicators

Panel A:

\begin{tabular}{|c|c|c|c|c|c|c|c|}
\hline \multirow{4}{*}{ 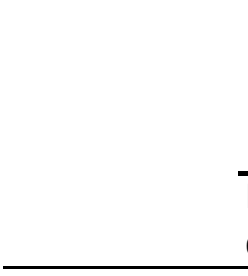 } & \multirow[t]{3}{*}{ Dependent variable } & \multicolumn{2}{|c|}{ Shopping } & \multicolumn{2}{|c|}{ Singing } & \multicolumn{2}{|c|}{ Story telling/reading } \\
\hline & & (1) & (2) & (3) & (4) & (5) & (6) \\
\hline & & OLS & IV & OLS & IV & OLS & IV \\
\hline & $\begin{array}{l}\text { Individual formal } \\
\text { child care usage }\end{array}$ & $\begin{array}{l}-0.137^{\star \star} \\
(0.000)\end{array}$ & $\begin{array}{l}-0.197 \\
(0.152) \\
\end{array}$ & $\begin{array}{l}0.079^{\star \star \star} \\
(0.027)\end{array}$ & $\begin{array}{c}0.131 \\
(0.130) \\
\end{array}$ & $\begin{array}{l}0.049^{* \star} \\
(0.020)\end{array}$ & $\begin{array}{l}-0.025 \\
(0.104)\end{array}$ \\
\hline \multirow[t]{18}{*}{ Individual controls } & Immigration & -0.036 & -0.039 & $-0.076^{\star}$ & $-0.074^{*}$ & -0.044 & -0.047 \\
\hline & background & $(0.045)$ & $(0.046)$ & $(0.042)$ & $(0.042)$ & $(0.035)$ & $(0.036)$ \\
\hline & Mother's age (in & $-0.032^{\star}$ & $-0.031^{*}$ & 0.020 & 0.018 & 0.013 & 0.015 \\
\hline & years) & $(0.017)$ & $(0.018)$ & $(0.021)$ & $(0.021)$ & $(0.014)$ & $(0.015)$ \\
\hline & Mother's age & $0.000^{\star \star}$ & $0.000^{\star}$ & 0.000 & 0.000 & 0.000 & 0.000 \\
\hline & squared (in years) & $(0.000)$ & $(0.000)$ & $(0.000)$ & $(0.000)$ & $(0.000)$ & $(0.000)$ \\
\hline & M other married & 0.006 & 0.004 & $0.12^{\star \star \star}$ & $0.112^{\star \star \star}$ & $0.052^{\star}$ & $0.048^{\star}$ \\
\hline & and cohabiting & $(0.035)$ & $(0.036)$ & $(0.034)$ & $(0.035)$ & $(0.028)$ & $(0.029)$ \\
\hline & Number of children & 0.001 & -0.002 & -0.022 & -0.019 & $-0.035^{\star \star \star}$ & $-0.039^{\star \star \star}$ \\
\hline & in the household & $(0.014)$ & $(0.015)$ & $(0.017)$ & $(0.018)$ & $(0.012)$ & $(0.013)$ \\
\hline & Child's age (in & $-0.002^{\star \star \star}$ & -0.002 & $-0.006^{\star \star \star}$ & $-0.007^{\star \star \star}$ & -0.001 & 0.000 \\
\hline & months) & $(0.001)$ & $(0.002)$ & $(0.001)$ & $(0.001)$ & $(0.001)$ & $(0.001)$ \\
\hline & Good / excellent & $0.106^{\star \star \star}$ & $0.105^{\star \star \star}$ & $0.079^{\star \star}$ & $0.079^{\star \star}$ & 0.025 & 0.024 \\
\hline & maternal health & $(0.033)$ & $(0.033)$ & $(0.031)$ & $(0.031)$ & $(0.024)$ & $(0.024)$ \\
\hline & University Degree & $-0.137^{\star \star \star}$ & $-0.132^{\star \star \star}$ & $0.071^{\star \star}$ & $0.066^{\star}$ & $0.114^{\star \star \star}$ & $0.121^{\star \star \star}$ \\
\hline & 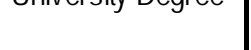 & $(0.033)$ & $(0.037)$ & $(0.032)$ & $(0.034)$ & $(0.020)$ & $(0.023)$ \\
\hline & Child is female & 0.024 & 0.023 & $0.106^{\star \star \star}$ & $0.106^{\star \star \star}$ & 0.015 & 0.015 \\
\hline & & $(0.026)$ & $(0.026)$ & $(0.025)$ & $(0.025)$ & $(0.019)$ & $(0.019)$ \\
\hline \multirow[t]{17}{*}{ Regional controls } & Unemployment & 0.007 & 0.007 & -0.004 & -0.005 & -0.006 & -0.006 \\
\hline & rate & $(0.008)$ & $(0.008)$ & $(0.007)$ & $(0.007)$ & $(0.006)$ & $(0.006)$ \\
\hline & Net migration rate & $9.582^{\star \star}$ & $9.350^{\star \star}$ & -2.526 & -2.321 & -0.859 & -1.149 \\
\hline & 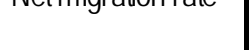 & $(4.518)$ & $(4.580)$ & $(3.730)$ & $(3.751)$ & $(3.718)$ & (3.688) \\
\hline & Female population & $4.856^{\star \star \star}$ & $4.835^{\star \star \star}$ & 1.394 & 1.413 & -0.143 & -0.170 \\
\hline & aged 20-49 & $(1.631)$ & $(1.626)$ & (1.385) & (1.388) & $(1.085)$ & $(1.086)$ \\
\hline & Female population & $4.024^{\star \star \star}$ & $3.950^{\star \star \star}$ & 0.843 & 0.908 & -0.422 & -0.514 \\
\hline & aged 65+ & $(1.432)$ & $(1.441)$ & $(1.205)$ & $(1.221)$ & $(0.954)$ & (0.953) \\
\hline & Fertility rate & 0.006 & 0.005 & 0.003 & 0.004 & -0.002 & -0.003 \\
\hline & & $(0.006)$ & $(0.006)$ & $(0.005)$ & $(0.005)$ & $(0.004)$ & $(0.004)$ \\
\hline & Female & $-0.392^{\star *}$ & $-0.396^{\star \star \star}$ & -0.175 & -0.172 & -0.004 & -0.008 \\
\hline & employment rate & $(0.159)$ & $(0.158)$ & $(0.142)$ & $(0.142)$ & $(0.121)$ & (0.123) \\
\hline & Constant & $-2.864^{\star *}$ & $-2.821^{\star \star \star}$ & -0.336 & -0.374 & 0.968 & 1.022 \\
\hline & & $(1.281)$ & $(1.280)$ & $(1.106)$ & $(1.111)$ & $(0.865)$ & $(0.867)$ \\
\hline & $\mathrm{N}$ & 1401 & 1401 & 1401 & 1401 & 1401 & 1401 \\
\hline & Prob. $>$ F & 0.0000 & 0.0000 & 0.0000 & 0.0000 & 0.0000 & 0.0000 \\
\hline & $\mathrm{R}^{2}$ & 0.1211 & 0.1184 & 0.1151 & 0.1125 & 0.0735 & 0.0647 \\
\hline
\end{tabular}


Panel B:

\begin{tabular}{|c|c|c|c|c|c|}
\hline \multirow{5}{*}{ 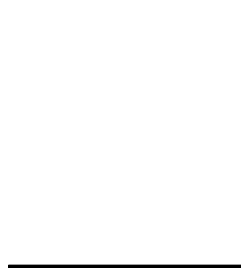 } & \multirow[t]{3}{*}{ Dependent variable } & \multicolumn{2}{|c|}{ Playground visits } & \multicolumn{2}{|c|}{ Watching television } \\
\hline & & (7) & (8) & (9) & (10) \\
\hline & & OLS & IV & OLS & IV \\
\hline & Individual formal & -0.022 & $0.312^{\star}$ & -0.001 & $0.302^{\star}$ \\
\hline & child care usage & $(0.03)$ & $(0.17)$ & $(0.03)$ & $(0.16)$ \\
\hline \multirow[t]{18}{*}{ Individual controls } & Immigration & $0.086^{\star}$ & $0.100^{\star \star}$ & -0.007 & 0.006 \\
\hline & background & $(0.04)$ & $(0.05)$ & $(0.05)$ & $(0.05)$ \\
\hline & Mother's age (in & $-0.04^{\star}$ & $-0.049^{* *}$ & 0.007 & -0.001 \\
\hline & years) & $(0.02)$ & $(0.02)$ & $(0.02)$ & $(0.02)$ \\
\hline & Mother's age & 0.000 & $0.001^{\star *}$ & 0.000 & 0.000 \\
\hline & squared (in years) & $(0.00)$ & $(0.00)$ & $(0.00)$ & $(0.00)$ \\
\hline & Mother married & -0.033 & -0.019 & -0.037 & -0.024 \\
\hline & and cohabiting & $(0.04)$ & $(0.04)$ & $(0.04)$ & $(0.04)$ \\
\hline & Number of children & -0.010 & 0.005 & -0.024 & -0.010 \\
\hline & in the household & $(0.02)$ & $(0.02)$ & $(0.02)$ & $(0.02)$ \\
\hline & Child's age (in & $-0.003^{\star \star \star}$ & $-0.005^{\star \star \star}$ & $0.003^{\star \star \star}$ & 0.000 \\
\hline & months) & $(0.00)$ & $(0.00)$ & $(0.00)$ & $(0.00)$ \\
\hline & Good / excellent & 0.047 & 0.049 & -0.025 & -0.023 \\
\hline & maternal health & $(0.04)$ & $(0.04)$ & $(0.04)$ & $(0.04)$ \\
\hline & University Dearee & -0.035 & -0.066 & $-0.209^{\star \star \star}$ & $-0.238^{\star \star \star}$ \\
\hline & & $(0.04)$ & $(0.04)$ & $(0.04)$ & $(0.04)$ \\
\hline & Child is female & -0.020 & -0.016 & -0.031 & -0.028 \\
\hline & & $(0.03)$ & $(0.03)$ & $(0.03)$ & $(0.03)$ \\
\hline \multirow[t]{17}{*}{ Regional controls } & Unemployment & 0.011 & 0.008 & 0.006 & 0.004 \\
\hline & rate & $(0.01)$ & $(0.01)$ & $(0.01)$ & $(0.01)$ \\
\hline & Netmiarat & 2.479 & 3.787 & 4.219 & 5.406 \\
\hline & & $(4.94)$ & (5.10) & (4.62) & $(4.86)$ \\
\hline & Female population & 1.446 & 1.569 & -0.845 & -0.734 \\
\hline & aged 20-49 & $(1.69)$ & $(1.76)$ & $(1.64)$ & (1.75) \\
\hline & Female population & 0.986 & 1.402 & -0.864 & -0.486 \\
\hline & aged 65+ & $(1.46)$ & (1.54) & $(1.40)$ & (1.51) \\
\hline & Ferility rate & $0.01^{*}$ & $0.013^{\star \star}$ & $-0.011^{*}$ & -0.007 \\
\hline & & $(0.01)$ & $(0.01)$ & $(0.01)$ & $(0.01)$ \\
\hline & Female & -0.179 & -0.160 & -0.023 & -0.005 \\
\hline & employment rate & $(0.17)$ & $(0.17)$ & $(0.16)$ & $(0.17)$ \\
\hline & Constant & 0.104 & -0.139 & 1.594 & 1.373 \\
\hline & & $(1.34)$ & $(1.39)$ & $(1.30)$ & $(1.40)$ \\
\hline & $\mathrm{N}$ & 1401 & 1401 & 1401 & 1401 \\
\hline & Prob. $>$ F & 0.0000 & 0.0000 & 0.0000 & 0.0000 \\
\hline & $\mathrm{R}^{2}$ & 0.0698 & 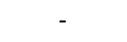 & 0.0784 & 0.0033 \\
\hline
\end{tabular}

Notes: standard errors are in parentheses

*** statistically significant at the $1 \%$ level

** statistically significant at the $5 \%$ level

* statistically significant at the $10 \%$ level

Source: authors’ calculations 
Table 5 shows only those models in which the variable capturing formal child care usage is statistically significant in at least one regression model, i.e., either in the OLS model or in the IV model. Again, the IV models are estimated using the procedure with the manual probit first stage fitted values as an instrument, as elaborated on above. Results from those models in which the child care variable is neither significant in the OLS nor in the IV regression are available upon request.

In Table 5, all the models are estimated using the same number of observations. The only difference between the models in columns (2), (4), (6), (8) and (10) is the respective dependent variable. Therefore, the first stage probit model is the same for all of the IV models shown in this table. Also, the first stage probit model is the same as for the models employing the interaction index as the dependent variable - this first stage probit model is shown in column (4) of Table 4. As discussed before, the instrument satisfies the relevance condition, so that there is no need to be concerned about a weak instrument. All the models presented in Table 5 are highly statistically significant (see Prob. > F, which is always equal to 0.0000 ) and explain between 0.3 and $12.1 \%$ of the variation in the data. It should be borne in mind, though, that $\mathrm{R}^{2}$ is not a particularly meaningful goodness of fit measure in linear probability models. In column (8), it is even suppressed in the output which occurs in case $\mathrm{R}^{2}$ is negative.

The OLS regression in column (1) in Table 5 shows that mothers who place their child in formal child care take him or her shopping less often. In fact, the probability that they take their child shopping daily or several times a week falls by almost 14 percentage points if the child attends formal child care, the effect being statistically significant at the $5 \%$ level. Once individual formal child care usage is instrumented by local formal child care usage rates (see column (2)), the coefficient increases by 6 percentage points but becomes statistically insignificant at conventional levels. 
The simple OLS regression of the frequency a mother sings to her child is reported in column (3). It reveals that mothers placing their child in formal care sing to him or her more often; the relevant coefficient is statistically significant at the $1 \%$ level. The probability of her singing to the child daily or several times a week increases by almost 8 percentage points if her child is placed in formal care. However, this effect turns insignificant in the IV regression presented in column (4) - it seems as if the plain OLS regression suffers from endogeneity or omitted variable bias. Maybe mothers who are prone to place their child in day care have some unobserved characteristics which also make them more likely to sing to their child. The same result is found for the frequency a mother tells her child stories or reads to him or her: The OLS model in column (5) predicts that mothers whose children attend formal care are by 5 percentage points more likely to perform this activity often than other mothers. This effect is statistically significant at the $5 \%$ level; but, once more, it becomes insignificant in the IV model (see column (6)).

When looking at the frequency of a mother taking her child to the playground and the frequency of watching television together with her child, the reverse pattern is found. In the OLS regressions in columns (7) and (9) no significant impact of formal child care usage on the respective mother-child interaction indicator is found. In contrast, the corresponding IV estimates shown in columns (8) and (10) do reveal a statistically significant (at the $10 \%$ level) impact of formal child care usage on interaction frequency. Mothers whose child attends formal care are 31 percentage points more likely to take their child to the playground either daily or a couple of times per week and roughly 30 percentage points more likely to watch television with him or her frequently. Again, the OLS regressions seem to suffer from omitted variable bias, but this time the confounding factors obfuscate the influence of individual formal child care usage on the frequency of going to the playground and watching 
television together. The statistically significant impact of individual formal child care usage on these mother-child interaction indicators is only revealed in the IV regressions.

In general, in Table 5, the coefficients estimated by the IV approach differ from the OLS estimates. Presumably, the OLS models are estimated inconsistently because of reverse causality or omitted variable bias. The difference in the magnitude of the estimates delivered by OLS and IV may also be due to the two estimators producing different effects: In general, the OLS estimator delivers average treatment effects, while the IV estimator only delivers average treatment effects under strong assumptions. In the present context, the IV estimator delivers local average treatment effects instead, as explained in the previous section. Presumably, part of the difference between OLS and IV results is due to OLS estimating average and IV estimating local average treatment effects.

Felfe and Lalive (2011) argue that formal child care facilities facing excess demand assign slots to those children who were put on the list early. Also, children may jump the waiting list depending on the working status of their parents. This system favours children of families with a privileged socio-economic status, who are more likely to sign up their child early and, therefore, face a higher probability of being assigned a slot. Expanding local formal child care slots (due to data availability presently approximated by local formal child care usage rates) then also enables socio-economically unprivileged families to place their children in formal care (cf. Felfe and Lalive 2011, pp. 8 and 18).

The average treatment effect resulting from the OLS estimation would thus be the effect of formal child care usage on families with a rather privileged socio-economic status, whereas the local average treatment effect resulting from the IV estimation would be its effect on mothers with a rather unprivileged socio-economic background. Comparing the results of the OLS and the corresponding IV estimates in Table 5 suggests that the effect of placing their child in formal care is much higher for mothers who would not per se place their child in 
formal care, but only do so as a consequence of increasing local formal child care rates (e.g., because coverage is expanded by creating more slots). For example, in the case at hand it seems that formal child care usage reduces the probability of a mother taking her child shopping often by more if she is a "marginal user" of child care.

Again, the covariates' coefficients should be interpreted rather conservatively as they might not be estimated consistently. Nevertheless, some statistically significant covariates are worth mentioning. OLS and IV regressions show that the probability a mother reads to her child very often decreases the more children she has. Conversely, the probability of her reading and singing to her child increases if she is married and cohabiting with her spouse and her child is female. Women are more likely to take their children to the playground but less likely to sing to them if they have an immigration background, i.e., they immigrated to Germany after 1948. Moreover, the probability a mother takes her child to the playground frequently decreases with maternal age whereas the probability of frequent singing or shopping decreases with her child's age. What is more, married women cohabiting with their spouse are more likely than others to sing or read to their child more often, as are mothers who hold a university degree. On average, the probability of a mother taking her child shopping often is lower if she is a university graduate whereas the probability of her singing or telling stories to the child frequently increases. Also, mothers holding a university degree are less likely to watch television with their child frequently. Mothers rating their current health status as predominantly positive are more likely to take their child shopping and to sing to him or her on a regular basis.

In the regression analyses for the remaining interaction variables, formal child care usage turns out to be statistically insignificant. Taken together, in several regressions child care does not have a statistically discernible effect on mother-child interaction. Part of this result may be due to the fact that the dependent variables only contain information on how often a 
specific activity is performed. As elaborated on in the previous section, this information is used to create binary variables indicating whether an activity is performed often or seldom / not at all. However, the information at hand may be too imprecise to produce statistically significant results with regard to many mother-child interaction indicators.

In order to examine the sensitivity of the estimation results presented in the previous section with regard to the respective model specification, we ran robustness checks to bolster the reliability of these results. In particular, we carried out three specification checks: Firstly, we entered all continuous independent variables in the OLS and IV with a first stage probit estimation models presented in this section in logarithms. Secondly, we checked if the results varied markedly when the first stage of IV models was estimated with an OLS estimator instead of the probit estimator used above. Overall, these analyses suggest that the results presented in this section are robust to these alterations.

Thirdly, we reran all regression analyses solely for either 2-3 year olds, the Western part of Germany, or 2-3 year olds in the West: One might argue that the supply of child care slots (as proxied by local formal child care usage rates) only influences individual formal child care usage in case of excess demand (cf. Felfe and Lalive 2012, p. 3). If there are no supply constraints, parents are free to place their child in formal care or not. According to this argument, our instrument would only be valid considering the Western part of Germany since, due to historic reasons, the demand for child care slots is usually met by the supply of slots in the East. Mostly, demand is also met by supply in the West for 5-6 year olds. This is why specification checks are carried out using the three different sub-samples named above. Basically, the results found in this section hold when considering these sub-samples only, although the coefficients are estimated less precisely which may be due to the reduced number of observations. The corresponding results are available on request. 


\section{Conclusion}

The present paper examines how placing their children in formal day care affects mothers' mental and physical health and mother-child interaction. Both maternal health and motherchild interaction in turn influence child outcomes. Therefore, it is important to assess the impact of formal child care usage on mothers' health and interaction with their children.

The results indicate that maternal mental health is not affected by whether the child attends formal care or not in all model specifications. A different pattern emerges concerning maternal physical health. The specification employing an IV estimator yields a statistically highly significant influence of individual child care usage on the corresponding mother's physical health. The coefficient has a negative sign and is of considerable size compared to the remaining coefficient estimates in this model. In short, mothers’ physical condition seems to suffer from their children attending formal care. It should be borne in mind though that this estimate represents a local average treatment effect.

With regard to mother-child interaction, the influence of individual formal child care usage on an interaction index is assessed. The coefficient of interest is statistically significant in the IV model where individual child care usage is instrumented by local formal child care usage rates. To get a more differentiated picture, the indicators making up the interaction index are each examined separately. For five of them, either the OLS or the IV estimate of the effect of individual formal child care usage is statistically significant: A mother whose child attends formal care takes him or her shopping significantly less often, but takes him or her to the playground more frequently. Moreover, those mothers usually sing to their children, tell or read stories to them and watch television together with them more often than mothers whose child is not placed in formal child care.

Overall, the results call for further investigations. As discussed above, the coefficient on individual formal child care usage in the regression model analysing maternal physical health 
is of considerable magnitude. Additionally, the sign of this coefficient is negative, which raises the question as to the reasons for this negative impact of formal child care usage on mothers’ physical condition. Furthermore, it might be enlightening to examine mother-child interaction with a data set containing more precise indicators and information on motherchild interaction. The present data set allows assessing the quantity dimension of interaction only. Nonetheless, the quality dimension of interaction is no less important and will need to be considered in future analyses. In order to extract more results from the SOEP data set, also another instrument could prove to be successful as well. Due to the work that still needs to be done in this field, further research is needed to make giving advice on family policies possible.

\section{Literature}

Almond, D. \& Currie, D. (2010), Human Capital Development Before Age Five, NBER Working Paper No. 15827.

Amemiya, T. (1981), Qualitative response models: A survey, Journal of Economic Literature 19/4, pp. 1483-1536.

Andersen, H., Mühlbacher, A., Nübling, M., Schupp, J. \& Wagner, G. (2007), Computation of Standard Values for Physical and Mental Health Scale Scores Using the SOEP Version of SF-12v2, Schmollers Jahrbuch 127/1, pp. 171-182.

Angrist, J. \& Pischke, J. (2009), Mostly Harmless Econometrics. An Empiricist's Companion, Princeton: Princeton University Press.

Baker, M., Gruber, J. \& Milligan, K. (2008), Universal Child Care, Maternal Labor Supply, and Family Well-Being, Journal of Political Economy 116/4, pp. 709-745.

Booth, C., Clarke-Stewart, K., Vandell, D., McCartney, K. \& Owen, M. (2002), Child-Care Usage and Mother-Infant “Quality Time”, Journal of Marriage and Family 64/1, pp. 16-26.

Brodeur, A. \& Connolly, M. (2012), Do Higher Childcare Subsidies Improve Parental Wellbeing? Evidence from Québed’s Family Policies, IZA Discussion Paper No. 6804.

Caruso, D. (1996), Maternal Employment Status, Mother-Infant Interaction, and Infant Development in Day Care and Non-Day Care Groups, Child \& Youth Care Forum 25/2, pp. 125-134. 
Chatterji, P., Markowitz, S. \& Brooks-Gunn, J. (2011), Early Maternal Employment and Family Wellbeing, NBER Working Paper No. 17212.

Felfe, C. \& Lalive, R. (2011), How Does Early Child Care Affect Child Development?, mimeo.

Felfe, C. \& Lalive, R. (2012), Early Child Care and Child Development: For Whom it Works and Why, IZA Discussion Paper No. 7100.

Heckman, J. \& Vytlacil, E. (2005), Structural Equations, Treatment Effects, and Econometric Policy Evaluation, Econometrica 73/3, pp. 669-738.

Herbst, C. \& Tekin, E. (2012), Child Care Subsidies, Maternal Well-Being, and Child-Parent Interactions: Evidence from Three Nationally Representative Datasets, NBER Working Paper No. 17774.

Husted, A. \& Rosenkrantz-Aronson, S. (2005), Mothers' Time with Infant and Time in Employment as Predictors of Mother-Child Relationships and Children's Early Development, Child Development 76/2, pp. 467-482.

Lange, J., Riedel, B., Fuchs-Rechlin, K., Schilling, M. \& Leu, H. (2008), http://www.bmfsfj.de/doku/Publikationen/zahlenspiegel2007/01-Redaktion/PDF-

Anlagen/Gesamtdokument\%2cproperty\%3dpdf\%2cbereich\%3dzahlenspiegel2007\%2csprach e\%3dde\%2crwb\%3dtrue.pdf, Zahlenspiegel 2007. Kindertagesbetreuung im Spiegel der Statistik, accessed: 30/04/2012.

Minkovitz, C., Strobino, D., Scharfstein, D., Hou, W., Miller, T., Mistry, K. \& Swartz, K. (2005), Maternal Depressive Symptoms and Children's Receipt of Health Care in the First 3 Years of Life, Pediatrics 115/2, pp. 306-314.

National Institute of Child Health and Human Development Early Childcare Research Network (NICHD) (1999a), Child Care and Mother-Child Interaction in the First 3 Years of Life, Developmental Psychology 35/6, pp. 1399-1413.

National Institute of Child Health and Human Development Early Childcare Research Network (NICHD) (1999b), Chronicity of Maternal Depressive Symptoms, Maternal Sensitivity, and Child Functioning at 36 Months, Developmental Psychology 35/5, pp. 1297-1310.

National Institute of Child Health and Human Development Early Childcare Research Network (NICHD) (2003), Early Child Care and Mother-Child Interaction from 36 Months through First Grade, Infant Behavior \& Development 26/3, pp. 345-370.

Petterson, S. \& Albers, A. (2001), Effects of Poverty and Maternal Depression on Early Child Development, Child Development 72/6, pp. 1794-1813.

Riedel, B., Gadow, T., van Santen, E., Fuchs, K., Schilling, M. \& Leu, H. (2005), http://www.bmfsfj.de/doku/Publikationen/zahlenspiegel2005/01-Redaktion/PDF-Anlagen /Gesamtdokument,property=pdf,bereich=zahlenspiegel2005,sprache=de,rwb=true.pdf, Zahlenspiegel 2005. Kindertagesbetreuung im Spiegel der Statistik, accessed: 30/04/2012. 
Stock, J. \& Watson, M. (2012), Introduction to Econometrics, $3^{\text {rd }}$ edition, Boston: Pearson.

Socio-Economic Panel (SOEP), Data for years 1984-2010, Version 27, SOEP, 2011, doi:10.5684/soep.v27.

U.S. Department of Health and Human Services, Administration for Children and Families (2010), http://www.acf.hhs.gov/programs/opre/hs/impact_study/reports/impact_study/hs_ imp\%20act_study_final.pdf, Head Start Impact Study. Final Report, accessed: 28/04/2012.

Wagner, G., Frick, J. \& Schupp, J. (2007), The German Socio-Economic Panel Study (SOEP) - Scope, Evolution and Enhancements, Schmollers Jahrbuch 127/1, pp. 139-169.

Wooldridge, J. (2002), Econometric Analysis of Cross Section and Panel Data, Cambridge Massachusetts: MIT Press.

Wooldridge, J. (2006), Introductory Econometrics. A Modern Approach, $3^{\text {rd }}$ edition, Mason Ohio: Thomson South-Western. 